DOI: $10.14451 / 1.181 .387$

\title{
ВНЕШНИЙ ДОЛГ РОССИЙСКОЙ ФЕДЕРАЦИИ В УСЛОВИЯХ ФИНАНСОВЫХ ОГРАНИЧЕНИЙ
}

\section{(C) 2019 Константинова Екатерина Олеговна}

студентка 3 курса, профиль обучения «Финансы и кредит», направление обучения «Экономика» Самарский государственный экономический университет, Россия, Самара

E-mail: konstantinova-14@yandex.ru

\section{(c) 2019 Валиева Елизавета Николаевна}

доктор экономических наук, профессор

Самарский государственный экономический университет, Россия, Самара

E-mail: valievaen2012@yandex.ru

В данной статье рассматривается структура внешнего долга Российской Федерации, проводится анализ его динамики за 2009-2019 гг. Исследуются показатели долговой устойчивости РФ, производится их сравнение с показателями ряда других стран. Уделяется особое внимание внешнему долгу органов государственного управления, строится модель, позволяющая прогнозировать его динамику

Ключевые слова: внешний долг РФ, долговая устойчивость, прогноз внешних государственных заимствований

На современном этапе развития внешнеэкономических отношений одним из ключевых факторов макроэкономической стабильности в стране является эффективное обслуживание внешнего долга. Позиция национальной экономики на долговом рынке оказывает существенное влияние на бюджетную систему страны, состояние ее валютных резервов, стабильность ее национальной валюты, уровень процентных ставок, инвестиционный климат и другие параметры рынка. Сложно прогнозируемые перспективы современной глобальной экономики явля- ются еще одним фактором, обусловливающим актуальность данной проблематики.

Внешний долг представляет собой обязательства страны в иностранной валюте, которые возникают в процессе осуществления ее экономической деятельности. В состав внешнего долга Российской Федерации входят задолженность органов государственного управления, Центрального банка, банков и прочих секторов экономики (рис. 1).

Из диаграммы видно, что наибольший удельный вес внешнего долга РФ приходится на

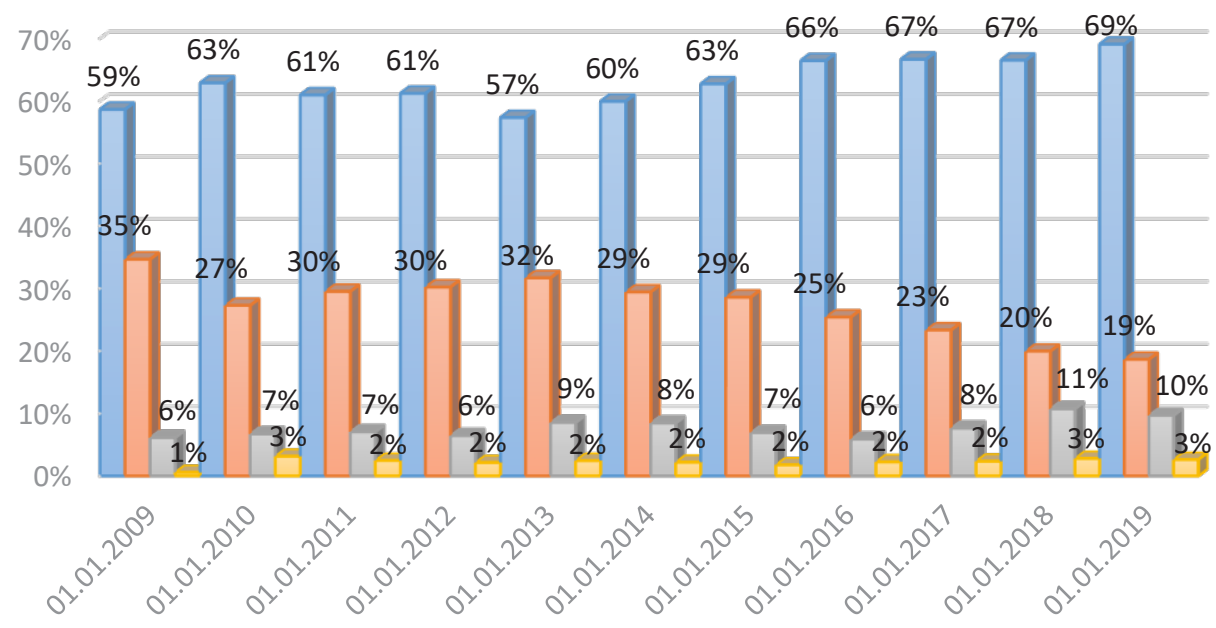

$\square$ Прочие секторы $\square$ Банки $\square$ Органы государственного управления $\square$ Центральный банк

Puc. 1. Динамика структуры внешнего долга РФ, за период 2009-2019 гг. (\%) Источник: данные Центрального банка России [1] 
прочие секторы экономики - в среднем 63\% за исследуемый период. Стоит обратить внимание на динамику удельного веса задолженности государственных органов. В течение последнего десятилетия удельный вес обязательств органов государственного управления в среднем составляет $8,5 \%$ и не превышает $11 \%$ внешнего долга страны. Таким образом, российские органы власти ориентируются преимущественно на внутренний финансовый рынок при выборе источников финансирования дефицита бюджетов.

Для анализа динамики объемов внешнего государственного долга в Российской Федерации за 2009-2019 годы были использованы данные Банка России с изменениями на 01.03.2019 г. (рис.2).

Из приведенной выше диаграммы видно, что с 2010 года сумма внешнего долга РФ постепенно увеличивалась и в 2014 достигла своего наибольшего значения в 728864 млн. долларов США. Это может быть обусловлено рядом факторов, в том числе снижением темпов экономического роста, падением цен на нефть и газ, ужесточением политики банковского сектора. После присоединения Крыма Россия столкнулась с волной санкций США, Канады, Евросоюза и ряда других стран, в том числе к ограничениям на мировом финансовом рынке, что привело к сокращению объема внешнего долга на 18\% в 2015 году, на $14 \%$ в 2016. Инвестиционный рейтинг РФ представлялся рейтинговыми агентствами как негативный, более того, была ограничена выдача кредитов крупным российским банкам с государственным участием, крупнейшие системы платежных карт заблокировали банковские операции. Для сокращения дефицита бюджета была совершена заморозка курсовой разницы нефтяных компаний и пенсионных накоплений граждан страны. В 2017 году снижение внешнего долга произошло лишь на 1\% (или на 6737 млн. долларов США) по сравнению с предыдущим годом, а в 2018 сумма увеличилась на 1\% (или на 6351 млн. долларов США). Были введены санкции со стороны США, запретившие участвовать в проектах крупных энергетических российских компаний своим гражданам и организациям. Сужение внешнеэкономических связей, импортозамещение, погашение срочных обязательств по долговым обязательствам в иностранной валюте привели к тому, что в начале 2019 года сумма внешнего долга сократилась на 64063 млн. долларов США. Повышение суверенного рейтинга РФ со спекулятивного до нижней ступени инвестиционного уровня способствовало росту спроса на внутренние долговые бумаги государства со стороны, в том числе иностранных инвесторов, заинтересованных в высокой доходности российских государственных облигаций. В результате потребность РФ в заемных средствах полностью удовлетворяется на внутреннем финансовом рынке. Отсутствие реакции инвесторов на американские ограничения на операции с облигациями федерального правительства позволяет предположить, что существующее положение дел сохраниться в среднесрочной перспективе.

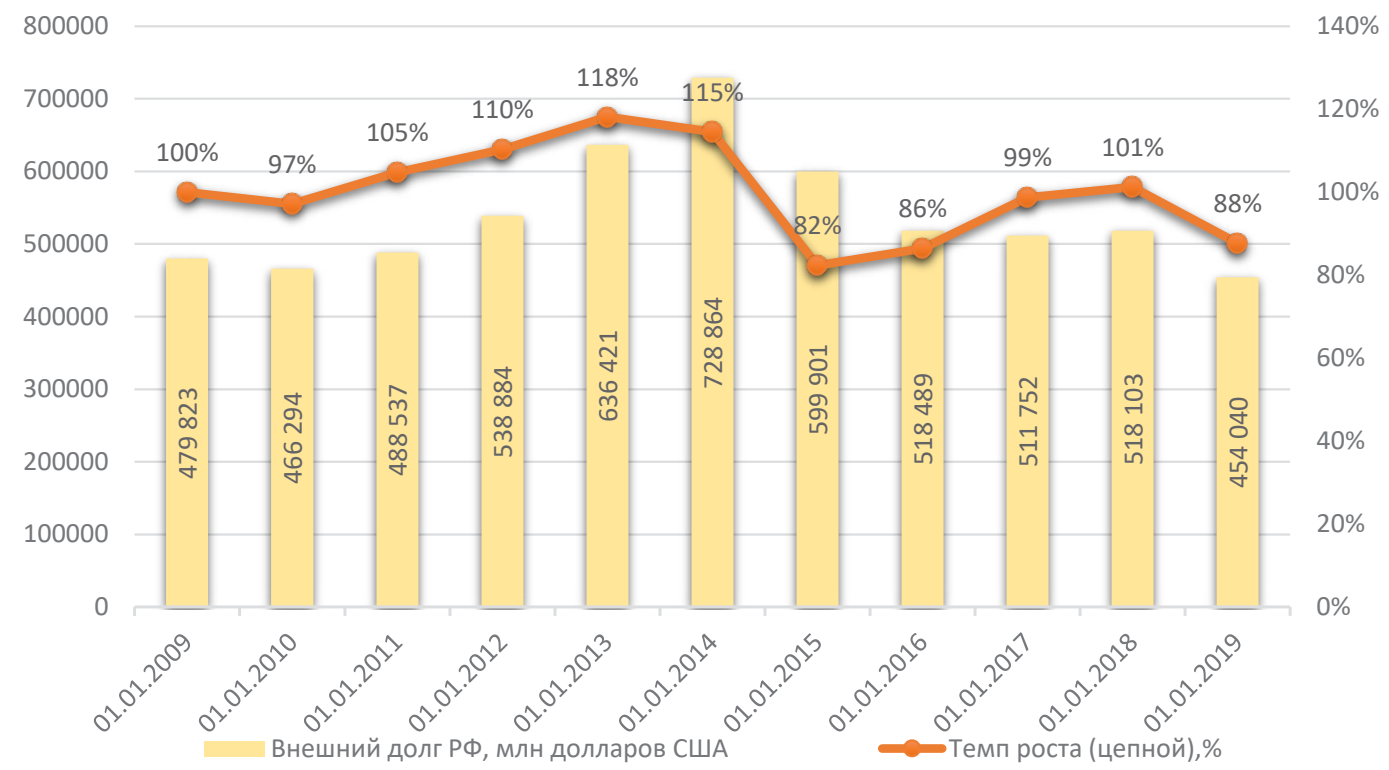

Pис. 2. Динамика внешнего долга РФ, за период 2009-2019 гг. (млн. долларов США;\%) 
Для оценки внешнего долга страны в международной практике рассчитывают ряд характеризующих его индикаторов, способствующих выявлению уязвимости бюджетной, финансовой сферы и частного сектора экономики [2] (табл. 1). Наиболее часто используют коэффициент отношения внешнего долга к ВВП, характеризующий платежеспособность государства.

Согласно пороговым значениям Международного валютного фонда в 2010-2014 гг. и в 2017-2018 гг. долговая устойчивость Российской Федерации обладала низкой степенью риска по коэффициентам «Внешний долг к ВВП» и «Внешний долг к объему экспорта товаров и услуг», в то время как в 2009, 2015 и в 2016 году она достигла средней степени риска. Коэффициент «Платежи по внешнему долгу к объему экспорта товаров и услуг» достиг своего среднего нормативного значения только лишь 2018 году. По сравнению с многими развитыми странами в конце 2018 года показатели долговой устойчивости по России отличаются в позитивную сторону (табл. 2).

По представленным показателям можно сделать вывод, что в настоящий момент внешние заимствования РФ обладают низкой степенью риска (в 2018 году темпы роста ВВП превысили темпы роста внешнего долга), а управление долгом является эффективным.

Далее остановимся на внешнем долге федеральных и субфедеральных органов государственной власти. В процессе бюджетного планирования формируются статьи доходов и

Таблица 1. Показатели долговой устойчивости РФ

\begin{tabular}{|c|c|c|c|c|c|}
\hline Дата & $\begin{array}{c}\text { Внешний долг к } \\
\text { ВВП,\% }\end{array}$ & $\begin{array}{c}\text { Внешний долг к } \\
\text { объему экспор- } \\
\text { та товаров и } \\
\text { услуг,\% }\end{array}$ & $\begin{array}{c}\text { Платежи по } \\
\text { вннему долгу } \\
\text { к ВВП,\% } \\
\text { внешнему долгу } \\
\text { объему экспор- } \\
\text { та товаров и } \\
\text { услуг,\% }\end{array}$ & $\begin{array}{c}\text { Вушу най долг на } \\
\text { доллары Сшан, }\end{array}$ \\
\hline 01.01 .2009 & $37,7 \%$ & $135,9 \%$ & $12,6 \%$ & $44,9 \%$ & 3261 \\
\hline 01.01 .2010 & $32,2 \%$ & $110,5 \%$ & $10,3 \%$ & $35,7 \%$ & 3420 \\
\hline 01.01 .2011 & $26,2 \%$ & $93,9 \%$ & $8,5 \%$ & $31,0 \%$ & 3766 \\
\hline 01.01 .2012 & $29,1 \%$ & $108,0 \%$ & $9,4 \%$ & $34,6 \%$ & 4441 \\
\hline 01.01 .2013 & $31,7 \%$ & $123,2 \%$ & $10,1 \%$ & $39,7 \%$ & 5071 \\
\hline 01.01 .2014 & $29,0 \%$ & $106,7 \%$ & $8,7 \%$ & $31,9 \%$ & 4100 \\
\hline 01.01 .2015 & $38,0 \%$ & $132,0 \%$ & $9,4 \%$ & $32,6 \%$ & 35340 \\
\hline 01.01 .2016 & $39,4 \%$ & $153,9 \%$ & $10,2 \%$ & $40,2 \%$ & 3485 \\
\hline 01.01 .2017 & $32,9 \%$ & $125,9 \%$ & $8,5 \%$ & $33,1 \%$ & 3526 \\
\hline 01.01 .2018 & $27,1 \%$ & $89,3 \%$ & $6,6 \%$ & $21,4 \%$ & 3092 \\
\hline
\end{tabular}

Источник: данные Центрального банка России

Таблица 2. Показатели внешнего долга некоторых стран мира (4 кв. 2018 г.)

\begin{tabular}{|l|c|c|}
\hline \multicolumn{1}{|c|}{ Название страны } & Внешний долг к ВВП, \% & $\begin{array}{c}\text { Внешний долг на душу населения, } \\
\text { доллары США }\end{array}$ \\
\hline США & 96,3 & 60031 \\
\hline Великобритания & 297,3 & 69014 \\
\hline Германия & 138,7 & 86759 \\
\hline Франция & 210,7 & 261820 \\
\hline Нидерланды & 492,0 & 31664 \\
\hline Япония & 80,4 & 46755 \\
\hline Испания & 161,7 & 38877 \\
\hline Италия & 116,7 & 522877 \\
\hline Ирландия & 710,9 & 6921680 \\
\hline Люксембург & 6096,9 & 3309 \\
\hline Россия & 29,0 & \\
\hline
\end{tabular}

Источник: данные с сайта Всемирного банка [3] 
расходов государства на определенный период времени. Достичь идеальных моделей функционирования, когда расходы страны соответствуют доходам (сбалансированный бюджет) или когда доходы превышают расходы (профицит бюджета), в современных условиях бывает практически невозможно. При дефиците бюджета для финансирования своей деятельности государству приходится прибегать к поиску дополнительных источников доходов. Одним из них может являться внешнее заимствование у других стран, международных финансовых организаций или у частных кредиторов [4]. С одной стороны, внешний займ предоставляет возможность получения государством дополнительных финансовых ресурсов для погашения своих обязательств, для своего успешного функционирования, а также для обеспечения стабильного экономического роста в целом. Одновременно с этим происходит укрепления авторитета страны и ее валюты за счет своевременного выполнения обязательств, что способствует улучшению внешнеторговых связей на мировом рынке, и наблюдается повышение уровня инвестиционной активности. Однако, получение внешних заемных средств требует своего обслуживания, что сказывается на будущих расходах бюджета. Возникает проблема постепенного возрастания задолженности государства по своим обязательствам, что может привести к его зависимости от других государств или международных финансовых организаций. В долгосрочной перспективе это может повлиять на темпы экономического роста, состояние бюджетной системы, уровень потребления. Таким образом, внешние государственные займы могут оказывать как положительное, так и отрицательное влияние на социально-экономические процессы страны, так как чем больше сумма долга, тем больше финансовые возможности правительства, но и тем существеннее долговая нагрузка на будущие поколения налогоплательщиков.

В процессе управления государственным долгом применяют ряд методов прогнозирования. Для определения прогнозного значения на 2020 год были построены линии тренда (табл. 3).

Динамика объема внешнего государственного долга лучшим образом описывается построенной нами полиномиальной линией тренда, с наибольшим коэффициентом детерминации $\mathrm{R}^{2}=0,2887$ (рис. 3).

Из построенной диаграммы видно, что объ-

Таблица 3. Линии тренда динамики государственного внешнего долга РФ

\begin{tabular}{|c|l|l|c|}
\hline № & \multicolumn{1}{|c|}{ Тип тренда } & \multicolumn{1}{|c|}{ Уравнение } & $\mathrm{R}^{2}$ \\
\hline 1 & Линейный & $\mathrm{y}=4,0358 \mathrm{x}-126496$ & $\mathrm{R}^{2}=0,1912$ \\
\hline 2 & Логарифмический & $\mathrm{y}=169432 \ln (\mathrm{x})-2 \mathrm{E}+06$ & $\mathrm{R}^{2}=0,1945$ \\
\hline 3 & Полиномиальный 2-й степени & $\mathrm{y}=-0,0028 \mathrm{x}^{2}+239,44 \mathrm{x}-5 \mathrm{E}+06$ & $\mathrm{R}^{2}=0,2887$ \\
\hline 4 & Степенной & $\mathrm{y}=4 \mathrm{E}-16 \mathrm{x}^{4,3244}$ & $\mathrm{R}^{2}=0,2366$ \\
\hline 5 & Экспоненциальный & $\mathrm{y}=550,55 \mathrm{e}^{0,0001 \mathrm{x}}$ & $\mathrm{R}^{2}=0,2329$ \\
\hline
\end{tabular}

Источник: расчеты авторов

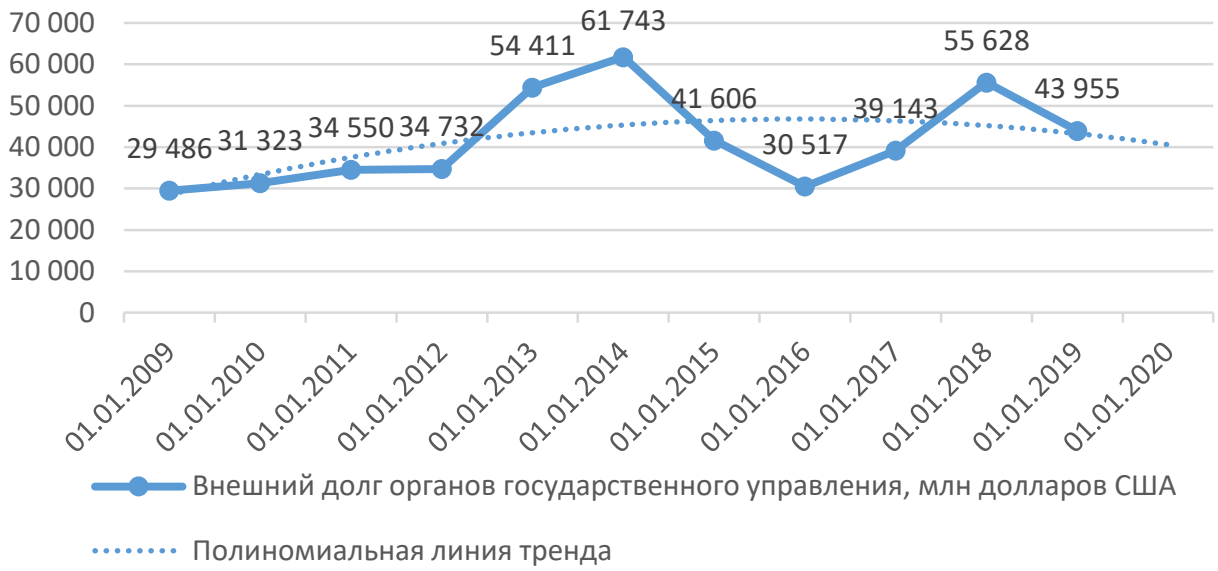

Puc. 3. Динамика внешнего долга государственных органов власти РФ, за период 2009-2019 гг. (\%) Источник: данные Центрального банка, расчеты авторов 
ем внешней задолженности органов государственного управления должен уменьшиться к 2020 году, и данная тенденция сохранится.

Таким образом, в настоящее время в условиях внешне экономической дезинтеграции и внутренней финансовой нестабильности правительству РФ удалось обеспечить устойчивость бюджетной системы, в том числе за счет эффективного управления государственным долгом. Изменение объема внешнего долга России с 2009 года происходило разнонаправлено. На сегодняшний день прослеживается тенденция к его снижению, что свидетельствует об удовлетворении потребностей органов государствен- ной власти РФ в заемных средствах на внутреннем финансовом рынке. Индикаторы долговой устойчивости согласно значениям Международного валютного фонда обладают низкой степенью риска и в сравнении с многими развитыми странами имеют позитивный характер. Финансовая независимость должна способствовать достижению национальных целей в экономике и социальной сфере. Корреляционно-регрессионное моделирование свидетельствует о сохранении тенденции снижения объема внешнего государственного долга России в среднесрочной перспективе.

\section{Библиографический список}

1. Центральный банк Российской Федерации.- URL: http://www.cbr.ru/statistics

2. Международные стандарты высших ревизионных учреждений ISSAI 5411 Показатели долга. Издательство: Международная организация высших ревизионных учреждений, ИНТОСАИ, 2010. С.5-7 [Электронный ресурс]. URL: http://www.intosai.org/fileadmin/downloads/downloads/1_about_us/ISSAIs/RU_ISSAI_5411.pdf

3. Всемирный банк.-URL: https://www.worldbank.org/

4. Пахмутов В.Н. Государственный долг РФ: Об аспектах управления внешним государственным долгом в условиях экономической нестабильности // Научный журнал. 2016. № 7(8). С.53-55. 